\title{
Readmisiones hospitalarias en recién nacidos egresados de una sala de alojamiento conjunto
}

\author{
NAVARRO E. ${ }^{1}$, MENDIETA E. ${ }^{1}$, MIR R. ${ }^{1}$, CÉSPEDES E. ${ }^{1}$, CABALLERO BC. ${ }^{1}$ \\ 1. Departamento de Neonatología. Cátedra de Pediatría. Centro Materno Infantil. Hospital de Clínicas. Facultad de Ciencias \\ Médica. Universidad Nacional de Asunción. Paraguay.
}

\section{RESUMEN}

Introducción: La readmisión neonatal es un tema muy importante con morbilidad significativa y costosa responsabilidad, constituye un especial desafío para el pediatra, debido a la inespecificidad y labilidad con que el RN reacciona ante diferentes noxas y la variedad de patologías que pueden presentarse de manera similar. Objetivo: Conocer las causas de reingreso, las características perinatales y la morbimortalidad de una población de recién nacidos readmitidos en el primer mes de vida y analizar las estrategias posibles que resulten en la mejor atención de la madre y el RN en la sala de alojamiento conjunto. Material y métodos: Estudio prospectivo, analítico, observacional, incluyeron todos los recién nacidos egresados del Servicio de alojamiento conjunto y readmitidos en el Departamento de Neonatología del Centro Materno Infantil (San Lorenzo), en los primeros 28 días de vida, en el periodo comprendido de enero del 2004 a junio del 2005. Resultados: Total de RN readmitidos 51. Promedio de edad materna 24 años (16-41), 76\% de las madres presentaron CPN suficiente, en el grupo de pacientes readmitidos el $40 \%$ tuvieron CPN insuficientes y $30 \%$ en el límite (4). El 57\% (29/51) nuligesta, 20\% primigesta, nacieron por cesárea el 52\% de los RN. Peso de nacimiento promedio $3189 \mathrm{~g}$. DS \pm 593 , edad gestacional promedio 38 semanas $\mathrm{DS} \pm 2,41 \%$ fueron $\mathrm{RN}$ casi de término y limítrofe (35-37 sem.). 63\% masculinos, el 100\% presentaron Apgar de 8/9. Edad media al alta 3 días \pm 1 , el $100 \%$ con lactancia materna exclusiva, días de vida al reingreso $9.3 \pm 4$. Los diagnósticos principales fueron: hiperbilirrubinemia $59 \%$, de los cuales el $90 \%$ fue sin incompatibilidad y sin hemólisis, el $99 \%$ requirió sólo luminoterapia y un paciente exanguinotrasfusión. El 18\% reingresó por mala técnica alimentaría, el 16\% (8) con diagnóstico de malformaciones congénitas mayores, dos pacientes fallecieron, constituyendo el 3.9\% del total. Conclusiones: Las causas de readmisión hospitalaria en este grupo de RN fueron hiperbilirrubinemia y mala técnica alimentaría; la gravedad de la readmisión se asoció a diagnóstico de infecciones y malformaciones congénitas.

(Palabras claves: readmisión, alojamiento conjunto, morbimortalidad, recién nacido.) Pediatr. (Asunción), Vol. 33; No 1; 2006

ESTE TRABAJO LO PUEDE ENCONTRAR EN EXTENSO EN WWW.SCIELO.CL 